\title{
O TERRORISMO INTERNACIONAL E A CORTE INTERNACIONAL DE JUSTIÇA
}

\author{
Guido Fernando Silva Soares \\ Professor Titular do Departamento de Direito \\ Internaciona! e Vice-Diretor da Faculdade de \\ Direito da Universidade de São Paulo
}

\begin{abstract}
Resumo:
Jurisdição, competência e atuação da Corte Internacional de Justiça perante o terrorismo internacional. A tipificação do terrorismo na ótica do Direito Internacional comparado às cortes internacionais existentes na atualidade.

Abstract:

Jurisdiction, accrual and performance of International Criminal Court against international terrorism. The tipification of the terrorism in International Law comparated to the International Courts actually existent.
\end{abstract}

Unitermos: terrorismo; Corte Internacional de Justiça; soluções de litígio; solução por órgãos judiciários internacionais.

1. O exame da eventual atuação da Corte Internacional de Justiça, no que se refere ao combate que hoje se trava contra o terrorismo internacional, deve ser enquadrado, a partir do exame dos poderes daquele tribunal internacional, no que respeita à sua jurisdição e competência, não-só nos termos do seu Estatuto e da jurisprudência internacional na matéria, mas, igualmente, num quadro analítico mais geral, comparativamente às outras cortes internacionais existentes na atualidade. Por outro lado, a tipificação do terrorismo, na ótica do Direito Internacional, coloca alguns pressupostos jurídicos, que se tornam necessários, desde o momento em que se analisam não só as condições para o exercício da jurisdição daquele tribunal internacional, como também seu posicionamento como um dos meios existentes na panóplia dos meios de soluções pacíficas de controvérsias entre Estados. As soluções de controvérsias por órgãos judiciários internacionais, por suas características, constitui um método de solução regulado, na sua essência, por normas jurídicas, que se apresentam com uma certa rigidez formal na regulamentação dos seus procedimentos, as quais são, sobretudo, caracterizadas como regras processuais preexistentes aos mencionados litígios. 
2. Comparativamente aos outros meios de soluções de litigios,' a solução por órgãos judiciários internacionais, possui menor criatividade que os demais (negociações diplomáticas, bons oficios, mediação, conciliação, arbitragens interestatais institucionais ou "ad hoc"), em particular, no que respeita a procedimentos a serem seguidos e às soluções a serem encontradas no correr ou ao final dos outros métodos (que a doutrina classifica como meios políticos ou diplomáticos, em confronto com os meios judiciários). Sendo assim, a análise da matéria do presente estudo, deve ser enquadrada sob duas óticas: a) a dos poderes da Corte Internacional de Justiça, conforme fixados pelo Direito Internacional, e b) aquela relativa à natureza jurídica dos litígios que poderão ser eventualmente submetidos ao exame dela.

3. A Corte Internacional de Justiça, instituída a 26 de junho de 1945 , no momento em que os Estados subscreviam a Carta de São Francisco, ou seja, naquele mesmo instante em que instituíam a Organização das Nações Unidas, se encontra definida no art. 92 daquele tratado multilateral, como "o principal órgão judiciário das Nações Unidas"2 O mesmo art. dispõe que ela "funcionará de acordo com o Estatuto anexo, que é baseado no Estatuto da Corte Permanente de Justiça Internacional" o qual "faz parte integrante da presente Carta". Trata-se, assim, de um órgão destinado à aplicação das soluções judiciárias, naqueles litígios entre Estados, o qual herdaria do primeiro tribunal internacional instituido nas relações internacionais globais ${ }^{3}$, a Corte Permanente de Justiça Internacional, criada em 1920, por mandamento do Tratado de Versalhes, de 1919, a estrutura, a composição, as regras relativas a competência e jurisdição, bem como a própria jurisprudência judiciária ${ }^{4}$ elaborada por aquele tribunal internacional, que tinha atuado no Entre Guerras.

I. Veja-sc nosso estudo: "Solução e Prevenção de Litigios Internacionais: Tipologias e Caracteristicas Atuais" In: Araminta de Azevedo Mcrcadante c Josć Carlos de Magalhãcs, coordenadores, Solução c Prevenção de Litigios Internacionais, v. II, São Paulo, NECIM-Projeto CAPES c Porto Alegrc, Livraria do Advogado Editora, 1999.

2. O texto da Carta da ONU, da qual faz parte integrante o Estatuto da Corte Internacional de Justiça, cncontra-se apud Vicente Marotta Rangel, Dircilo c Relações Intcrnacionais, São Paulo, Editora Revista dos Tribunais, 6a cdição revista c atualizada.

3. Na verdade, o primeiro tribunal judiciário internacional na História da Humanidade, foi instituido no inicio do Sćc. XX, na América Central, com a denominação de Corte de Justiça Centro-Americana, de breve cxistência. Veja-sc: o trabalho do Prof. Fredys Orlando Sorto, "América Central: Relações Internas c Crisc Politica: Soluçõcs Pacificas", Disscrtação de Mestrado cm Dircito Internacional, defendida a 07/ VI/1991, na Faculdade de Dircito da USP (Orientador: Prof. Dr. Josć Roberto Franco da Fonscca).

4. Empregamos a cxpressão "jurisprudência judiciária” para diferençá-la de outro tipo importante de repertórios de soluções de litígios cntre Estados, a "jurisprudência arbitral", conforme claborada por arbitragens internacionais, "ad hoc" ou aquela institucionalizada após a criaçào da Corte Permanente de 
4. A Corte Internacional de Justiça reflete, portanto, o desejo de os Estados estabelecerem um tribunal internacional, com juízes permanentes e uma jurisdição universal, não-conforme as realidades de 1945, mas tendo em vista a situação de um mundo imediatamente posterior à Primeira Guerra Mundial (que, a nosso ver, na verdade, é o fenômeno histórico que, verdadeiramente, inauguraria o Séc. XX). Tais razões explicam porque aqueles tribunais internacionais sejam omissos quanto às relevantes pessoas de Direito Internacional, algumas das quais já existiam, mas que seriam instituídas, em número crescente, logo após a Segunda Guerra Mundial, as organizações intergovernamentais. Tal lacuna diz respeito a dois aspectos: a) a falta de reconhecimento expresso dos atos expedidos por aquelas pessoas coletivas, como fontes das normas internacionais aplicáveis por aqueles tribunais (fenômeno este, contudo, que não tem causado qualquer empecilho a que a Corte Internacional de Justiça tenha aplicado as deliberações da Assembléia Geral ou do Conselho de Segurança da ONU, como autênticas normas do Direito Internacional), e b) a falta de um reconhecimento delas, como pessoas jurídicas capazes de integrar, por direito próprio, relações processuais submetidas à jurisdição contenciosa daqueles tribunais, tendo em vista os termos do art. $34, \S 1^{\circ}$ do Estatuto da CIJ, segundo o qual, "só os Estados poderão ser partes em questão perante a Corte"; contudo, nos termos do art. $65 \S 1^{\circ}$ do mesmo Estatuto, "a Corte Poderá dar parecer consultivo sobre qualquer questão jurídica a pedido do órgão que, de acordo com a Carta das Nações Unidas ou por ela autorizado, estiver em condições de fazer tal pedido" Sendo assim, tanto no pólo ativo, quanto no pólo passivo, as organizações intergovernamentais não podem figurar como partes, nos procedimentos contenciosos perante a Corte Internacional de Justiça, constituindo tal fato, um dos motivos de considerar-se a personalidade delas, como incompleta, comparativamente aos Estados ${ }^{5}$

Arbitragem, com sede na Haia, a partir de 1907. Neste último caso, não de trata propriamente de um tribunal, nem de um corpo permanente de árbitros julgadores, mas de um conjunto normativo de : a) regras para a instituição de um árbitro único ou de uma comissão de árbitros, a pedido de um Estado, cndereçado às autoridades internacionais cncarregadas daquela CPA, sob a ćgide do Governo dos Países Baixos; b) um rol com nomes de pessoas que cventualmente poderão ser indicadas como árbitros únicos ou como membros de uma comissão de árbitros (inclusive, na presidência dos trabalhos, caso haja uma impossibilidade de os Estados ou os árbitros cscolhidos chegarem a um consenso sobre tal função); b) regras que instituem autoridades internacionais com a função de receber e expedir notificações entre Estados, com a finalidade de propiciar à constituição de um árbitro único ou de uma comissão de vários árbitros; c) regras internacionais sobre os procedimentos prévios de instituição de um árbitro único ou de uma comissão de árbitros (prazos, medidas para complementar casos de falta de coopcração de outros Estados ou na impossibilidade de indicar-sc um árbitro pela parte ou um presidente de comissão de árbitros) c d) regras minimas, de naturcza opcional, sobre os procedimentos arbitrais a serem seguidos pclo(s) árbitro(s), caso os Estados partes na arbitragem não tenham cstatuido a respcito.

5. Veja-se nosso estudo "As ONGs e o Direito Internacional do Meio Ambiente". In: Revista de Dircito Ambiental, São Paulo, Ed. Revista dos Tribunais, ano 5, n. 17, janciro-março, 2000, pp. 21-64 
5. Na verdade, dos tribunais judiciários internacionais existentes na atualidade, outros há em que organizações intergovernamentais têm plena capacidade postulatória, em ambos os pólos. Destaquem-se aqueles existentes nas organizações intergovernamentais de integração econômica regional, do tipo mercado comum, a Comunidade Européia (Luxemburgo) e o Pacto Andino (Quito). No primeiro caso, após a instituição da Comunidade Européia do Carvão e do Aço, CECA, precursora da atual Comunidade Européia, fundada pelo Tratado de Paris de 18 de abril de 1951 (e que seria logo seguida pela instituição da Comunidade Econômica Européia, CEE e da Comunidade Européia de Energia Atômica, Euratom, ou CEEA, criadas pelo Tratado de Roma, de 25 de março de 1957), assistiu-se à instituição de uma corte comunitária, onde aquelas organizações intergovernamentais passaram a ter uma capacidade ativa $e$ passiva em procedimentos judiciais perante a mesma, em contenciosos em que figuram tanto os órgãos da Comunidade, quanto os Estados-Partes. Tratava-se da instituição de um tribunal permanente, com sede em Luxemburgo, hoje denominado Tribunal (ou Corte) da Comunidade Européia, com os propósitos de aplicar-se um Direito Internacional Público particular, ${ }^{6}$ de cunho econômico, e regional "ratione personae" na sua abrangência, bem como um Direito Supranacional inovador, que seria criado pelos órgãos instituídos, o Direito Comunitário, cuja finalidade era de reconstruir-se uma parte significativa de um Continente devastado pela Guerra de 1939-1945. Destaque-se que as normas do Direito Internacional Público comunitário, aperfeiçoadas pelas normas do próprio Direito Comunitário, conferiram um acesso direto e por direito próprio, sem a necessidade de qualquer interveniência de órgãos diplomáticos, a indivíduos e empresas ao Tribunal de Luxemburgo, conquanto restrito a matéria de Direito da Integração Econômica regional, em litígios em que pudessem figurar os Estados-Partes e os órgãos intergovernamentais instituídos.

\footnotetext{
6. Como se sabc, a partir da instituição das organizações intergovernamentais de integração cconômica regional, do tipo mercado-comum, passou-se a distinguir, claramentc, dois niveis das normas internacionais regionais: a) um dircito primitivo (consubstanciado nos tratados $\mathrm{c}$ acordos internacionais regidos pelo Dircito Internacional Público, como os atos de fundação, de instituição de órgãos internacionais, de admissão de novos membros, de modificações cstruturais relevantes na competência dos órgãos internacionais constituidos, ctc.) c b) um dircito derivado (consubstanciado nas decisões dos órgãos unipcssoais ou colctivos, no excrcicio das respectivas competências normativas c administrativas, instituidas conforme o referido dircito primitivo). A doutrina, para bem distinguir os tipos de tais normas internacionais, refere-sc às primciras, como normas do Dircito Internacional Público $\mathrm{c}$ às segundas, como um Dircito Supranacional. No caso da Europa Comunitária, a expressão "Direito Comunitário", ora designa todo o conjunto, ora o segundo tipo. Por outro lado, segundo determinadas concepções que pretendem analisar outros fenômenos de mercados-comuns no resto do mundo (como o Pacto Andino), cmpregam a expressào Dircito Supranacional, pela indelćvel marca regional c curopćia que o adjetivo "Comunitário" passou a cxprimir.
} 
6. Outro tribunal internacional em pleno funcionamento, nos dias correntes, o Tribunal Internacional do Direito do Mar, instituído pela Convenção das Nações Unidas sobre o Direito do Mar, firmada a 10 de outubro de 1982, em Montego Bay, com sede em Hamburgo, confere acesso unicamente aos Estados- Partes e àquelas entidades distintas dos Estados-Partes, expressamente previstas naquele tratado multilateral, nomeadamente a Autoridade Internacional dos Fundos Marinhos e a Empresa, nos termos do art. 20 do Estatuto daquele Tribunal (Anexo VI da mencionada Convenção). Sua competência é restrita a questões que envolvem Estados, em matéria de Direito do Mar, não-só compreendida na mencionada Convenção de Montego Bay, mas em outros tratados multilaterais anteriores, sobre o mesmo campo. ${ }^{7}$

7. No que respeita ao reconhecimento da personalidade dos indivíduos em Direito Internacional e seu eventual acesso a tribunais internacionais, pouco antes da instituição da Corte Européia de Luxemburgo, na Europa então dita "Ocidental", assistiu-se à instituição, em nível regional, de um tribunal regional, destinado a examinar violações aos direitos humanos. ${ }^{8}$ Tratava-se de uma Europa dilacerada pela Segunda Guerra Mundial, tanto do ponto de vista das violações gravíssimas dos valores fundamentais da pessoa humana, cometidos por alguns Estados europeus (em flagrante desrespeito a uma tradição constitucional européia, que se firmara na Europa, a partir das constituições escritas ou-não escritas dos Estados do continente europeu), quanto da total destruição da vida econômica daquele Continente, em virtude das operações bélicas. A reconstrução econômica da Europa, na verdade, deveria passar, necessariamente, pela reconstrução dos valores fundamentais da pessoa humana, os quais já contavam, na esfera normativa internacional, com a solene manifestação dos Estados então membros da ONU, na Declaração Universal dos Direitos do Homem, proclamada pela Assembléia Geral, a 19 de dezembro de 1948, e com a subscrição de

7. Veja-se nosso trabalho anteriormente citado, Dircito Internacional do Mcio Ambientc: Emcrgência, Obrigações c Responsabilidades, São Paulo, Atlas, 2001, cm particular, o Cap. 10: "Conteúdo das Obrigações no Direito Internacional do Meio Ambiente (IV): Deveres de Os Estados Absterem-se do Uso da Força, na soluções de Controvérsias sobre o Direito Internacional do Meio Ambiente", sobrctudo, na sua Scção 10.1: "Soluções de controvérsias previstas na Convenção das Nações Unidas sobre o Direito do Mar (Montego Bay, 1982), p. 660 c ss.

8. $\Lambda$ s inter-relações cntre as normas de proteção aos dircitos humanos, $\mathrm{cm}$ nível regional, $\mathrm{c}$ as normas originárias dos mecanismos das integração cconômica regionais, foram analisadas num nosso trabalho: "A União Européia, o Mercosul e a Proteção dos Direitos Humanos", claborado a partir da apresentação oral, no tema correspondente à sua denominação, cfetuada por ocasião do Scminário "Dircitos Humanos c Mercosul", organizado pela Procuradoria Gcral do Estado de São Paulo c pela Faculdade de Dircito da PUC-SP, de 07 a 09 de agosto de 2000, no "campus" desta Pontificia Universidade, cm São Paulo, SP. No prelo de publicação com aqucla denominação do seminário, sob responsabilidade da citada Procuradoria Geral do Estado de Sào Paulo. 
um primeiro tratado multilateral, a Convenção para a Prevenção e a Repressão do Crime de Genocidio, assinada poucos dias antes, a 11 de dezembro de 1948, em Paris. Sendo assim, ao mesmo tempo em que se reconstruíam as relações econômicas na Europa Comunitária, de forma inovadora, a proteção dos direitos humanos seria definida na Europa então Ocidental, por um tratado multilateral regional, a Convenção Européia para a Proteção dos Direitos Humanos e das Liberdades Fundamentais, assinada em Roma, a 04 de novembro de 1950. Na data de sua emergência, e por vários anos, aquela Convenção de Roma, de 1950, previa dois órgãos internacionais: a) uma Comissão diplomática composta de representantes dos Estados-Partes, a Comissão Européia dos Direitos Humanos e b) um Tribunal, composto de juízes permanentes, escolhidos dentre nacionais dos Estados-Partes, sediado em Estrasburgo, o qual poderia receber e julgar reclamações apresentadas diretamente por Estados-Partes ou pela referida Comissão (cuja principal incumbência seria, assim, de receber e encaminhar queixas de individuos ao referido Tribunal). Conforme escrevemos em trabalho anterior: “a partir de 1994 (Protocolo 11), e as posteriores modificações introduzidas pelo Acordo Europeu Relativo a Pessoas que Participam nos Procedimentos da Corte Européia dos Direitos Humanos, firmado em Estrasburgo, a 05 de maio de 1997" a referida Comissão Européia dos Direitos Humanos foi suprimida e "a Corte de Estrasburgo passou a ter plena competência para receber reclamações de individuos, contra qualquer Estado Partes na Convenção Européia, independentemente de sua nacionalidade deles, e tão somente, pela verificação de uma violação contra os mesmos cometida (jurisdição "ratione loci delicti commissi") ${ }^{9}$

8. O exemplo da Europa dos Direitos Humanos seria transposto para o Continente americano, com a assinatura e entrada em vigor da Convenção Americana de Direitos Humanos, adotada em San José da Costa Rica, a 22 de novembro de 1969, que até os dias de hoje, conserva a estrutura e os mecanismos originais: uma Comissão Interamericana de Direitos Humanos, sediada em Washington, junto da OEA e a Corte Interamericana de Direitos Humanos, um tribunal permanente, com sede em San José. Se o modelo europeu ocidental de um tribunal com sua jurisdição acionável por qualquer indivíduo, independentemente de sua nacionalidade, ainda não se verificou no Continente americano (tendo em vista que o acionamento da jurisdição da Corte Interamericana dos Direitos Humanos ainda depende de reclamações apresentadas por Estados-Partes e nos casos de reclamações individuais unicamente aquelas endossadas

9. Apud: "Solução e Prevenção de Litigios Internacionais: Tipologias e Caracteristicas Atuais", Id., Ibid., 1999, p. 53, "passim". 
pela referida Comissão Interamericana dos Direitos Humanos, sediada em Washington), pelo menos existe um tribunal regional, ao lado de uma comissão de representantes diplomáticos,. Contudo, na África, os caminhos para a proteção dos direitos humanos ficariam restritos à única existência de um órgão diplomático, a Comissão Africana dos Direitos Humanos, sediada em Adis Abeba, porém sem a previsão de qualquer tribunal regional, conforme as normas da Convenção Africana dos Direitos Humanos e dos Povos, adotada em Banjul, a 1981, como tal vigente até os dias correntes.

9. Deve ressaltar-se que, em nível global, em matéria de proteção aos dircitos humanos, existem tão-somente os mecanismos diplomáticos de verificação de adimplência das normas internacionais, através de comitês, compostos de funcionários dos Estados partes, sendo patente a inexistência de um tribunal permanente internacional, com uma jurisdição comparável à Corte Européia ou à Corte Interamericana. Na verdade, os tratados multilaterais de proteção aos direitos humanos, tanto os gerais, como os Pactos Internacionais das Nações Unidas de 1966, como os especiais (nomeadamente, a Convenção sobre Genocídio), instituíram os mencionados comitês diplomáticos, mas nenhum conseguiu um tribunal, a exemplo da Europa dos Direitos Humanos ou do Continente Americano. Conforme expusemos em trabalho anterior: "no que respeita às normas instrumentais, de instituição de mecanismos de controle e de aplicação das normas de direito material assim definidas, na esfera internacional global, não puderam eles ser tão eficazes quanto aqueles dos direitos internos das democracias da atualidade; na verdade, deve-se considerar que tais mecanismos dependem da aceitação dos Estados, que, nem sempre, se encontram dispostos a ceder parte das respectivas soberanias, em favor de órgãos internacionais, de composição multilateral e com poderes cogentes sobre os mesmos. Ademais de comitês diplomáticos previstos nos citados Pactos e na citada Convenção sobre Genocidio, o máximo que se conseguiu, foi a constituição pelo Conselho Econômico e Social da ONU, de uma Comissão dos Direitos Humanos, em 1946 (Resolução n. 5 da primeira sessão do ECOSOC), composta de representantes diplomáticos dos Estados," numa base de rotatividade de representações, de natureza permanente (reuniões ordinárias anuais por 40 dias) $e$ com uma jurisdição internacional, sediada em Genebra, mas com poderes de examinar a situação daqueles direitos em todo mundo e de apenas formular recomendações aos Estados, eventualmente inadimplentes de suas obrigações convencionais. Seria

10. Originariamente prevista para contar com 18 Estados, hoje conta com 53, desde 1990. Informaçõcs apud J. A. L.indgren Alves, Os Dircitos Humanos como Tema Global, São Paulo, Perspectiva c Brasilia, Fundação Alcxandre de Gusmão, 1994, p. 73. 
necessário esperar-se até o ano de 1998, para ver-se consagrada a instituição de um Tribunal Penal Internacional (Tratado de Roma de 17 de julho de 1998), de natureza permanente e jurisdição internacional, competente para conhecer e julgar os crimes de genocidio, os crimes contra a humanidade, os crimes de guerra e os crimes de agressão: nos dias correntes, à espera da entrada em vigor do tratado que o instituiu, o Tribunal será sediado na Haia, e terá uma jurisdição automática, ou seja, independentemente de qualquer aceitação "ad hoc" por parte dos Estados que dele farão parte, conquanto a matéria de sua competência esteja restrita aos crimes catalogados na Convenção de Roma, e não para qualquer outra violação de direitos humanos" "ll

10. Sem dúvida, foi a inquestionável experiência histórica da proteção dos direitos humanos na Europa Ocidental, que serviria de modelo às necessidades de constituir-se um mecanismo de acompanhamento e verificação da adimplência das normas internacionais, não unicamente regional, mas de abrangência universal, sobre temas correlatos e igualmente cada vez mais relevantes, nas relações internacionais do final do Séc. XX, os mencibnados crimes de genocidio, os crimes contra a humanidade, os crimes de guerra e os crimes de agressão. Na verdade, o julgamento por órgãos judiciários internacionais de violações de direitos humanos, perpetrados por autoridades dos Estados, no correr da segunda metade daquele Século, e com uma tipificação de maior gravidade, enquanto crimes internacionais, juntamente com a instituição de tipos criminais autônomos, tinham tido dois antecedentes históricos, o Tribunal de Nuremberg e o Tribunal de Tóquio, os quais, contudo, padeciam da falta de um consenso sobre sua legitimidade, quanto ao não- respeito à regra da anterioridade da definição do crime, no relativo à sua punibilidade. No caso de dois tribunais particulares existentes na atualidade, o Tribunal para os Crimes em Ruanda e o Tribunal para os Crimes na Ex-Iugoslávia, bem como no caso do Tribunal de Roma, de 1998, aquela regra do "nullum crimen nulla poena sine previa lege" foi cabalmente respeitada, tendo em vista que os julgadores foram instituídos, em matéria penal, ao mesmo tempo em que se definiam os tipos criminais, e tudo, com a necessária anterioridade ao acionamento dos mecanismos punitivos, no que respeita instituição dos tipos dos crimes e das penas a eles aplicáveis.

11. A instituição de tribunais internacionais com jurisdição sobre indivíduos, além daquelas matérias relativas a assuntos de integração econômica regional (restritos, ainda, a quadros normativos de uma integração mais pronunciada entre os Estados-Partes, como os modelos de mercado comum) e do campo da proteção dos

11. Guido F. S. Soares, “Uniüo Européia, Mercosul e Proteção dos Direitos Humanos”, Id., ibid., (no prelo). 
direitos humanos, não tem sido pacífica. O grande obstáculo a que se dê maior desenvolvimento ao tema da responsabilidade dos indivíduos, no Direito Internacional Público, repousa no fato de que este direito, por mais que se tenha aberto à pessoa humana (nos aspectos de proteção a seus direitos), ou a empresários, pessoas físicas ou jurídicas (enquanto agentes diretos da integração econômica), ainda repousa no postulado da plenitude dos direitos e deveres conferidos a Estados, entidades essas tal como definidas, de maneira formal, por suas normas, ou seja, Estados soberanos, como tal reconhecidos pela comunidade de outros Estados (e, portanto, estando excluídos agrupamentos ou quaisquer outras situações, nas quais não haja o reconhecimento da personalidade jurídica internacional, a exemplo os movimentos de libertação nacional).

12. No que respeita ao posicionamento dos indivíduos no Direito Internacional, nos casos fora do campo dos direitos humanos, cujas normas se destinam à proteção de direitos subjẹtivos, é mister considerar dois campos distintos: a) o campo geral da responsabilidade dos Estados, regido por usos e costumes internacionais, que se configura num sistema da denominada responsabilidade subjetiva ou por culpa e b) o campo novo e particular, do Direito Internacional do Meio Ambiente, constituído de normas especiais, em assuntos tópicos, que constitui o sistema da denominada responsabilidade objetiva ou por risco. A doutrina, em particular da Comissão de Direito Internacional das Nações Unidas, tem empregado a terminologia "responsabilidade internacional" tout court, para o primeiro caso, e para o segundo, "responsabilidade por atos não proibidos pelo Direito Internacional".

13. No primeiro campo, da responsabilidade geral, dita subjetiva ou por culpa, há o dever de reparar, desde que haja uma violação de uma norma internacional, violação essa que somente pode ser atribuída ao Estado, como um todo (portanto, sendo irrelevante serem atos do Executivo, Legislativo ou Judiciário dos Estados, ou da Administração Central ou Decentralizada ou de indivíduos sob a jurisdição dos Estados). Trata-se de um sistema complexo, tradicionalmente regido por usos e costumes internacionais, por uma farta jurisprudência arbitral e jurisprudencial internacional, e com a expressiva manifestação da doutrina dos internacionalistas da qual se destaca a obra de codificação empreendida pela Comissão de Direito Internacional das Nações Unidas, cujo resultado foi um Projeto de Convenção sobre Responsabilidade Internacional dos Estados, atualmente em exame pela Assembléia Geral das Nações Unidas. ${ }^{12}$ É necessário enfatizar que os indivíduos, sejam autores de ilícitos, sejam as vítimas, não

12. Veja-se scu texto no Ancxo E de nosso livro já mencionado: Dircito Internacional do Mcio Ambientc: Emergência, Obrigações, Responsabilidades, id. Ibid., que se encontra na Internet, no "site": www.atlasnct.com.br/guidosoares. 
têm um direito próprio de postulação de reivindicações frente a Estados, nem mesmo a possibilidade de figurarem como partes, em polos passivos, nos procedimentos diplomáticos ou jurisdicionais em que unicamente os Estados podem figurar como partes.

14. No segundo campo, da responsabilidade dita objetiva ou por risco, existe o dever de reparar, na medida em que se configura a hipótese do tipo definido na norma: a) um dano (independentemente de culpa), tipificado na norma, em virtude da prática de ato ou de omissão, (atos lícitos, porém danosos) portanto, atividade legítima, permitida pela norma, mas que pode causar um dano a outro Estado, a pessoas submetidas à jurisdição deste, ou a um bem protegido pelas normas internacionais (como os espaços internacionais comuns); b) a canalização da autoria do dano numa pessoa determinada, seja o Estado (no caso particular, o Estado lançador de um objeto espacial ${ }^{13}$ ), seja numa pessoa indigitada nos ordenamentos jurídicos nacionais (para citar, dentre as normas vigentes internacionalmente, o proprietário do navio que causa um acidente com o derramamento de óleo ao mar, ${ }^{14}$ o operador de uma central nuclear num acidente nuclear, ${ }^{15}$ ou dentre aquelas que se encontram no aguardo de uma vigência internacional, como o operador de um estabelecimento que lida com organismos geneticamente modificados $^{16}$ ); c) a denominada socialização do risco (obrigatoriedade de seguros privados, a serem complementados por fundos constituídos pelo Estado ou, internacionais, por Estados); d) as possibilidade rígidas de limitações da responsabilidade e das exonerações das obrigações de indenizar; e) a indicação dos tribunais nacionais competentes, com o prestígio conferido àqueles que confiram maiores facilidades às vítimas e, finalmente f) normas sobre o reconhecimento internacional das decisões dos judiciários internos, em outras jurisdições dos Estados partes nas convenções.

15. A distinção ganha relevância, na medida em que no sistema da responsabilidade subjetiva, unicamente os Estados podem figurar nas relações jurídicas,

13. Trata-sc da Convenção sobre Responsabilidade Internacional por Danos Causados por Objetos Espaciais, adotada conjuntamente cm Londres, Moscou c Washington, a 22 de março de 1972. Encontrasc promulgada no Brasil pelo Decreto $\mathrm{n}$. 71.981 de 22/ll1/1972.

14. Trata-se da Convenção Internacional sobre Responsabilidade Civil por Danos Causados por Poluição por Ólco, adotada cm Bruxclas, a 29 de novembro de 1969 (conlıccida por "CLC", sigla para "Civil Liability Convention"). No Brasil acha-se promulgada pelo Decreto n. 79.437 de 28/03/1977.

15. É o caso regulado pela Convenção de Vicna sobre Responsabilidade Civil por Danos Nucleares, adotada cm Vicna, a 21 de maio de 1963, sob a ćgide da AlEA. Encontra-se promulgada no Brasil, pelo Decreto n. 911 de 03/IX/1993.

16. Trata-sc de uma convenção regional curopćia, a Convenção de Lugano de 21 de junho de 1993 , “sobre Responsabilidade Civil por Danos Resultantes de Atividades Prejudiciais ao Mcio Ambicnte". Seu texto cicontra-se apud: 32 ILM 1228 (1993). 
que se constituem a partir da violação de uma norma: como já deixamos enfatizado, tanto os autores de um dano, decorrente de uma violação de um dever jurídico, quanto o destinatário do direito a uma reparação do dano (a vítima), devem ser Estados. Contudo, há alguns casos em que a norma internacional, no sistema geral da responsabilidade (responsabilidade por culpa), parece nomear uma pessoa de direito interno como diretamente responsável, como no caso de autoria de um dano, mesmo que o autor tenha sido um indivíduo suficientemente diferençado do Estado; contudo, em tais casos, a norma internacional atribui a responsabilidade por uma conduta daquela pessoa, diretamente ao Estado, nas condições que a norma internacional determina, das quais, a nacionalidade da pessoa ou a circunstância de a mesma encontrar-se sob sua jurisdição. No caso da vítima, no que respeita à responsabilidade em relação a um autor de um dano, que se encontre fora da jurisdição de um Estado, os direitos daquela deverão ser assumidos por um Estado, através do instituto da proteção diplomática; neste caso, um Estado, em geral o da nacionalidade da vítima, assume seus direitos e, em nome próprio, passa a postular sua defesa, frente a outros Estados, no foros unicamente reservados a Estados (negociações diplomáticas, bons oficios, mediação, conciliação e arbitragens entre Estados, e, enfim, as soluções perante tribunais judiciários internacionais).

16. Nos casos em que a norma internacional nomeia, de modo expresso, um indivíduo cuja conduta deve ser reprimida, (caso de traficantes de objetos de arte, de substâncias proibidas ao comércio internacional, como no narcotráfico ou, ainda, no combate à escravidão ou ao tráfico internacional de pessoas) ou cuja conduta é particularmente visada (as inúmeras menções ao comandante do navio, às autoridades portuárias e responsáveis por sinalizações de tráfego marítimo ou aéreo, existentes na Convenção de Montego Bay de 1982), a responsabilidade é sempre do Estado, e a norma limita-se a instituir para o Estado uma obrigação de resultado ${ }^{17}$ (ou seja, o dever de estabelecer normas ou mecanismos internos, que dêem eficácia, no ordenamento juridico nacional, à obrigação internacional que incumbe ao Estado, em particular, o exercício do "jus puniendi”).

17. O Antcprojeto da Comissào de Dircito Intcrnacional da ONU sobrc Responsabilidade dos Estados, assim dispõc, conforme a versão oficial cm cspanhol, no art. 21, cmentado "Violación de una obligación internacional que exige el logro de un resultado determinado". "verbis: "\$ lo . Hay violación por un Estado de una obligación internacional que le exige el logro, por el medio que elija, de un resultado determinado si el Estado, mediante el comportamiento observado, no logra el resultado que de él exige esa obligación. \$20 Cuando un comportamiento de Estado haya creado tuna situación que no esté én conformidad con el resultado que de è exige una obligación internacional, pero la obligación permita que ese resultado o un resultado equivalente pueda no obstante lograrse mediante un comportamiento ulterior del Estado, sólo hay violación de la obligación si el Estado tampoco logra mediante su comportamiento "ulterior el resultado que de él exige esa obligación" Cf.: Internct: www.atlasnct.com.br/guidosoares. 
17. Nas hipóteses que interessam ao Direito Internacional, particularmente ao combate ao terrorismo internacional, a situação é ainda mais complexa. O ramo do Direito Internacional Penal tem de conviver com um postulado inarredável de tudo quanto diga respeito à responsabilidade penal, que é, na sua essência, eminentemente individual. Por outro lado, falece ao Direito Internacional, um mecanismo de legitimação de um órgão central como o titular das funções de aplicar a sanção penal, que é o característico dos ordenamentos jurídicos nacionais: o monopólio e a exclusividade do poder público, no que se refere ao processo penal, tanto na aplicação da lei penal (definição das condutas e das penas a elas aplicáveis), quanto no sistema de fazer valer as sanções endereçadas aos indivíduos (execuções das penas). Nos casos tradicionais dos tratados multilaterais que definem os crimes internacionais, há o estabelecimento de normas de tipificação dos ilícitos, que passam a ser puníveis em qualquer lugar do mundo, claro está, nos espaços submetidos às soberanias somente dos Estados-Partes naqueles tratados $\mathrm{e}$, ainda, nas condições em que aqueles Estados se tenham submetido às normas internacionais (ou seja, em função da interpretação de eventuais reservas).

18. No campo do Direito Internacional Penal convencional, nos aspectos diretos relativos ao terrorismo, trata-se de um campo regido por poucas e precisas normas escritas de vocação universal: a) as convenções relacionadas à segurança da aviação civil internacional (Convenção sobre Infrações e Certos Atos Cometidos a Bordo de Aeronaves, adotada em Tóquio, a 14/09/1963, Convenção sobre a Repressão ao Apoderamento Ilícito de Aeronaves, assinada na Haia, a 16/12/19, a Convenção para' a Repressão de Atos Ilícitos contra a Segurança da Aviação Civil, assinado em Montreal, a 23/09/1971, e o Protocolo para a Repressão de Atos Ilícitos de Violência nos Aeroportos que Prestam Serviços à Aviação Civil Internacional, assinado, igualmente em Montreal, a 24/02/1988); b) as convenções relativas à segurança da navegação marítima (Convenção para a Repressão de Atos llícitos contra a Segurança da Navegação Marítima, assinada em Roma, a 19/03/1988, e o Protocolo para a Repressão de Atos Ilícitos contra a Segurança das Plataformas Fixas na Plataforma Continental, adotado em Roma, na mesma data); c) a relativa à segurança física de materiais nucleares (Convenção sobre a Proteção Física de Materiais Nucleares, assinada em Nova York, sob a égide da AG da ONU e em Viena, sede da AIEA, ${ }^{18}$ a 03/03/

18. A Agência Internacional de Energia Atômica, organização intergovernamental do sistema das Nações Unidas, com sede $\mathrm{cm}$ Vicna, tcm descnvolvido importante trabalho nos dois aspectos da segurança dos materiais nucleares $\mathrm{c}$ as instalações nucleares: a) os aspectos da scgurança fisica (prevenção de açõcs humanas de naturcza criminosa, ou, na terminologia utilizada: "muclear security") c b) os aspectos de segurança nuclear (contenção de radiação nuclcar $\mathrm{c}$ proteção dos trabalhadorcs $\mathrm{cm}$ atividades nucleares $\mathrm{c}$ do mcio ambiente circundantc às instalą̧õcs nuclearcs c ao mcio ambientc extcrior às mesmas: "nuclear safety"). 
1980); d) a sobre o seqüestro de pessoas relevantes para as relações internacionais, ou seja, de diplomatas (Convenção Internacional contra a Tomada de Reféns de 18/12/ 1979), e) as convenções relativas a explosivos (Convenção sobre a Marcação de Explosivos de Plástico para fins de Deteç̧ão, Montreal, a 01/03/1991 e a Convenção Internacional para a Repressão de Atentados Terroristas Cometidos com Bombas, Nova York, 15/12/1997) e, enfim, f) a Convenção Internacional para a Repressão de Financiamento ao Terrorismo, adotada em Nova York, a 09/12/1999. De âmbito regional, registrem-se a Convenção da OEA, para a Prevenção e Repressão de Atos de Terrorismo que Tomam a Forma de Crimes contra Pessoas ou Atos de Extorsão com Alcance Internacional, adotada em Washington, a 02/02/1971 (da qual o Brasil não é parte, nem participou de sua negeciação) e a Convenção Européia para a Repressão do Terrorismo, adotada pelo Conselho da Europa, em Estrasburgo, a 27/01/1977, já em vigor internacional, a partir de 03/08/1978.

19. Um exame dos textos mais importantes, em particular daquelas convenções com vigência internacional e grande número de Estados participantes, revela alguns pontos em comum, do quais, o mais importante é a consagração da regra da universalidade da punibilidade dos atos criminosos, independentemente do lugar da comissão do ilícito ou da nacionalidade do autor ou da vítima; contudo, o exercício do "jus puniendi" é deixado aos Estados-Partes, segundo os respectivos sistemas jurídicos nacionais. No fundo, consagra-se a norma definida por Hugo Grotius, "aut dedere, aut punire", ou seja, aqueles tratados multilaterais instituem um sistema de obrigações aos Estados-Partes de, ou extraditarem os suspeitos ou acusados dos atos ilícitos, ou, na impossibilidade de extradição (grande parte dos sistemas jurídicos nacionais, como o brasileiro, impedem a extradição de nacionais, ${ }^{19}$ ou como de alguns países de tradição islâmica, que exigem que seus nacionais sejam julgados por tribunais compostos de juízes da sua religião ${ }^{20}$ ), o dever de exercerem o "jus puniendi" (mesmo que o crime não tenha qualquer vínculo de conexão com o território ou a nacionalidade das vítimas ou da natureza nacional do bem protegido). Trata-se da consagração do princípio da denominada universalidade da jurisdição penal, no Direito brasileiro reconhecido como

19. No Brasil, a norma ć de naturcza constitucional, nos termos do inc. LI do art. 5.0 da Constituição Federal de 1988, verbis: "Nenhum brasileiro será extraditado, salvo o naturalizado, em caso de crime comum. praticado antes da naturalização, ou de comprovado envolvimento em tráfico ilicito de entorpecentes e drogas afins, na forma da lei"

20. Destaquem-se as exigências de alguns Estados de forte tradição islâmica, de que muçulmanos scjam julgados por tribunais muçulmanos. Tal fato scrá da maior importância no Caso Lockcrbic (Libia v. Rcino Unido c EUA), relatado nas conclusõcs destc trabalho. 
um dos casos de extraterritorialidade ${ }^{21}$ (submissão à lei brasileira dos crimes cometidos no estrangeiro), expressamente no Código Penal, art. $7^{\circ}$ inc. II. al. (a) (os crimes que, "por tratado ou convenção, o Brasil se obrigou a reprimir"), mas ainda dependente, no ordenamento jurídico brasileiro, de algumas condições que, de maneira unilateral, a lei brasileira exige (conforme $o \S 2^{\circ}$ daquele mesmo art. $\left.7^{\circ}\right)^{22}$

20. A grande dificuldade que se tem verificado na aplicação dos dispositivos dos tratados multilaterais que definem os crimes internacionais, se refere às questões das impossibilidades legais de extradição, segundo normas internas dos Estados, e, o que é mais grave, o fato de que alguns dos Estados de nacionalidade dos extraditandos, os considerarem como heróis, ou ainda, pelo fato de sua ação criminosa ser qualificada como um crime político. A qualificação de uma ação seja como crime político, seja como crime comum, tem seus reflexos na possibilidade ou-não de extradição do agente, e, ressalte-se, é, segundo as normas internacionais, um atributo do Estado onde se encontra fisicamente o extraditando, o qual, ao atribuir a este, de maneira unilateral, a qualificação de crime político, impediria sua extradição a outros Estados. $\mathrm{Na}$ verdade, a qualificação de atos como crimes políticos, tem contornos obscuros, é um ato discricionário dos Estados e, como já mencionado, se realiza através de decisões unilaterais dos Estados nos quais se encontram os citados extraditandos. Neste particular, ressalte-se o fato de ter sido o ponto central da Convenção Européia para a Repressão ao Terrorismo, assinada em Estrasburgo, a 27/01/1977, 23 a preocupação de "despolitizar" aqueles atos qualificados de terroristas (tirar-lhes a conotação de crime político), com a finalidade de permitir a mais ampla extradição dos implicados.

21. Por outro lado, os crimes políticos não-só impedem a extradição, como criam a situação de um dever de o Estado tratar os eventuais criminosos, como asilados territoriais, com direitos de proteção particular, nos ordenamentos jurídicos nacionais

21. Vcja-sc nosso trabalho "O Meio Ambiente e a Justiça no Mundo Globalizado". In. Justiça Pcnal: Críticas c Sugestões; 10 Anos da Constituição c a Justiça Pcnal: Mcio Ambientc, Drogas, Globalização c o Caso Pataxó. Coordenador: Jacques de Camargo Penteado. São Paulo, Editora Revista dos Tribunais, 1998, pp. 65-118.

22. Art. 7o § 2.0: Nos casos do inciso II, a aplicação da lei brasileira depende do concurso das seguintes condições: a) entrar o agente no território nacional; b) ser o fato punivel também no pais em que foi praticado; c) estar o crime entre aqueles pelos quais a lei brasileira autoriza a extradição; d) não ter sido o agente absolvido no estrangeiro ou não ter ai cumprido pena: e) não ter sido o agente perdoado no estrangeiro, ou, por outro motivo, não estar extinta a punibilidade, segundo a lei mais favorável.

23. Scu texto se encontra como Anexo ao artigo de Charles Valćc, La Convention Européenne pour la Répression du Terrorisme. In: Annuairc Français de Droit Intcrnational, Paris, Editions du CNRS, v. XXII, 1976, particularmentc, pp. 782-6. 
(direitos a uma vida normal, posto que a pessoa passaria a ter uma proteção do Estado que o asilou). $\mathrm{O}$ asilo territorial ${ }^{24}$ (na verdade, igualmente o asilo diplomático, ${ }^{25}$ que atribui os mesmos direitos nos ordenamentos internos, tão logo o asilado penetre no território do Estado asilante) é um instituto reconhecido pela Declaração Universal dos Direitos do Homem, no seu art. XIV, ${ }^{26}$ mas se encontra ausente dos dois Pacto das ONU, de 1966, e dos três grandes tratados multilaterais regionais sobre direitos humanos.

22. Quanto à questão da situação dos asilados nos ordenamentos jurídicos internos dos Estados, especial atenção deve ser dada aos países da América Latina: tanto o asilo territorial, quanto o asilo diplomático constituem uma longa tradição, desde a prática haurida na antiga União Panamericana, no Entre Guerras, e, na atualidade, encontram-se regidos por dois importantes tratados multilaterais regionais, votados sob a égide da Organização dos Estados Americanos, em Caracas, no mesmo dia (X Conferência Interamericana) a 28/03/1954: a Convenção sobre Asilo Diplomático e a Convenção sobre Asilo Territorial, as quais, no Brasil, foram conjuntamente promulgadas pelo Decreto n. 55.929 de 14/04/1965 27 O instituto do asilo não deve, na atualidade, ser confundido com o instituto do refúgio, ${ }^{28}$ este, um instituto relativamente

24. O asilo territorial ć concedido a uma pessoa que se encontra ilegalmente no território de um Estado (cntrada irregular), e tem por pressuposto uma situação de grave perturbação no Estado da nacionalidade do asilando, tendo por fim uma proteção de caráter humanitário àquela pessoa.

25. O asilo diplomático é aquele concedido nas Missõcs diplomáticas devidamente acreditadas nos Estados de nacionalidade do asilado, nas acronaves militares, belonaves ou acampamentos militares estrangeiros, autorizados a cstacionarcm num Estado.

26. Declaração Universal dos Dircitos do Homem, proclamada pcla Asscmblćia Gcral das Nações Unidas, cm 10/12/1948, art. XIV: " $\$$ 1" Todo homem, vitima de perseguição, tem o direito de procurar e de gozar asilo em outros paises. \$2.o Este direito nâo pode ser invocado em caso de perseguição legitimamente motivada por crime de direito comum ou por atos contrários aos objetivos e principios das Nações Unidas".

27. A situação dos asilados, no ordenamento juridico nacional do Brasil, se rege por dispositivos particulares do denominado Estatuto dos Estrangciros. Os refugiados se encontram disciplinados pela Lei n. 9.474 de 22/06/1997 "define mecanismos para a implementaçào do Estatuto dos Refugiados de 1957 c determina outras providências" Veja-se o trabalho de Fernando Fernandes da Silva, "A Proteção do Refugiado no Ordenamento Juridico Nacional: Fundamentos Constitucionais e as Medidas Legislativas e Administrativas Aplicáveis", In: Revista Trimestral de Dircito Público, São Paulo, Malhciros (no prelo).

28. As fundamentais diferenças podem ser assim csquematizadas: a) o asilo ć um ato discricionário dos Estados que o concedem; o refúgio é uma obrigação a que os Estados se submetcram a conceder; b) o asilo, na atualidade, com excç̧ão da Amćrica Latina (onde o assunto ć versado pclas duas citadas convençõcs regionais), ć regulado por usos c costumes diplomáticos, ao passo que o refúgio ć um instituto totalmente regulado por normas votadas pela ONU e pelo mencionado Tratado de 1951; d) o asilo, tem nitidas conotações de protcção humanitárias $\mathrm{cm}$ situações de cmergências politicas ( $\mathrm{cm}$ cspecial, de proteção a antigos dirigentes que foram apcados do poder, num movimento revolucionário, ou por golpes de Estado), ao passo que o refúgio tem outras finalidades (proteção das pessoas $\mathrm{cm}$ situações de instabilidade politica ou cconômica endógenas, cm determinadas partes do mundo, como no Continente africano). Veja-sc, Fernando Fernandes da Silva, 
novo no Direito Internacional, regulado por um tratado multilateral de vocação universal (conquanto a doutrina antiga considere "asilo" como sinônimo de "refúgio"), a Convenção Relativa ao Estatuto do Refugiado adotada em Genebra, a 28.07.1951 e Protocolo de Nova York sobre o Estatuto dos Refugiados, de 31/01/1967, por atos da própria $\mathrm{ONU}$, que administra o instituto, através de um seu organismo constituido em pela 14/12/1950 (Resolução n. 428,V) da Assembléia Geral, em 14/12/1950: o ACNUR (Alto Comissariado das Nações Unidas para os Refugiados), com sede em Genebra.

23. Ademais de tais percalços que o Direito Internacional enfrenta na luta contra o terrorismo internacional, no que se refere à atuação da Corte Internacional de Justiça, outro há que nos parece de grande significação: o fato de que a jurisdição da Corte Internacional de Justiça nem sempre poder exercitar-se de maneira automática, por provocação de um Estado ou de um grupo de Estado, contra a vontade de outro ou outros Estados.

24. A vontade dos litigantes, em qualquer pólo que se encontrem na relação processual, é muito importante na questão da determinação da jurisdição da Corte Internacional de Justiça. Em primeiro lugar, um Estado litigante tem o direito de indicar um juiz de sua nacionalidade para compor aquele tribunal no julgamento de um caso em que seja parte, na hipótese de inexistir um juiz seu nacional, ou ainda, há a possibilidade de a parte "ex adverso" contar com um juiz de sua nacionalidade na composição dos seus juizes (art. $31 \S 1^{\circ}$ do seu Estatuto). Em segundo lugar, a jurisdição da CIJ pode ser invocada em três hipóteses, nas quais a manifestação da vontade dos Estados é elemento essencial:

a) pelo depósito junto ao Secretário Geral da ONU, de uma declaração em que o Estado dê sua aceitação incondicionada da jurisdição da CIJ, no momento em que subscrever o Estatuto da CIJ ou a qualquer tempo. Trata-se do dispositivo do art. $36 \S 2^{\circ}$ do Estatuto da CIJ, denominado "cláusula facultativa de jurisdição obrigatória" (facultativa, porque os Estados têm a faculdade de adotá-la ou-não, e obrigatória, porque estabelece a jurisdição obrigatória da $\mathrm{CIJ}$ para os Estados que a adotarem da mesma forma $)^{29} \mathrm{Na}$ verdade, a cláusula não tem uma aceitação

29. Eis o tcor do art. $36 \$ 20$ do Estatuto da CIJ verbis: "Os Estados partes do presente Estatuto poderão, em qualquer momento, declarar que reconhecem como obrigatória "ipso facto" e sem acordo especial, em relação a qualquer outro Estado que aceita a mesma obrigação, a jurisdição da Corte, em todas as controvérsias de ordem juridica que tenham por objeto: a) a interpretação de um tratado; b) qualquer ponto de direito internacional; c) a existência de qualquer fato que, se verificado, constituiria violação de um compromisso internacional: d) a natureza ou extensão da reparação devida pela ruptura de um compromisso internacional" 
generalizada, ${ }^{(30)}$ sendo o Brasil um dos Estados que não-admite a jurisdição obrigatória "ipso jure" da CIJ;

b) pela subscrição de um acordo especial entre os Estados partes numa controvérsia, denominado "compromisso", (em francês e inglês: "compromis"), em tudo semelhante ao "compromisso" existente nas arbitragens entre Estados, ${ }^{(31)}$ pelo qual aqueles reconhecem a jurisdição da Corte, descrevem a controvérsia e os pontos em que se pede um pronunciamento da Corte, e indicam as normas aplicáveis (se o Direito Internacional Geral ou uma norma particular constante num tratado ou convenção internacional vigente entre as Partes), inclusive com a autorização para os juizes decidirem "ex aequo et bono" ou seja, por eqüidade; $\mathrm{e}$

c) na inexistência de qualquer título de justificação da jurisdição da CIJ, pela submissão da demanda por um Estado e pela aceitação expressa ou tácita da jurisdição da Corte, por outro Estado (trata-se do denominado princípio do "forum prorrogatum"). Nos casos de aceitação tácita, mencionem-se as hipóteses de haver entre os litigantes, num tratado sobre assuntos tópicos, uma cláusula denominada de solução pacífica de controvérsias, na qual haja menção à jurisdição da Corte Internacional de Justiça, como um dos meios para solucionar controvérsias na aplicação ou interpretação do dito tratado.

25. Mesmo que os Estados-Partes sejam depositantes da mencionada declaração junto ao Secretário Geral da $\mathrm{ONU}$, a prática tem revelado que a subscrição de um compromisso tem sido norma, no sentido de tornar mais clara a função dos juízes internacionais. Tal fato torna a atuação da Corte Internacional de Justiça muito mais aproximada à atuação de tribunais arbitrais, nos quais a instituição e investidura de pessoas, indivíduos ou comissões, com poderes de aplicar o direito, dependem da vontade dos litigantes. Claro está que nas hipóteses de ações de terrorismo atribuídos a um Estado, o exercício da jurisdição da Corte Internacional de Justiça estará dependente da manifestação da vontade daquele Estado!

26. Dadas tais características da atuação da Corte Internacional de Justiça (e o mesmo se diga da Corte Permanente de Justiça Internacional do Entre Guerras), e

30. São apenas 52 Estados aqueles que reconhecem a jurisdição obrigatória da $\mathrm{ClJ}$, dentre os quais, membros permanentes do Consclho de Segurança da ONU, somente o Reino Unido. Importante salientarsc a retirada da declaração de accitação compulsória da jurisdição da CIJ, pcla França, cm 10/91/1974 c pelos EUA cm 07/10/1985, após o julgamento de casos $\mathrm{cm}$ scu desfavor (respectivamente: o Caso dos Ensaios Nuclcarcs no Pacífico c Caso Nicarágua V. EUA).

31. Uma das principais diferenças de um compromisso numa arbitragem $\mathrm{e}$ do compromisso perante a CIJ, reside no fato de que neste, como regra, inexistem dispositivos relativos a procedimentos, uma vez que estes fazem parte do arcabouço institucional daquela Corte e se encontram no Estatuto c o no Regimento Interno deste tribunal internacional. 
aquelas outras, apontadas no início deste trabalho (relativas à impossibilidade de indivíduos ou grupos de indivíduos figurarem como partes nos seus procedimentos), muito dificilmente se poderia encontrar um precedente judicial que, por seus elementos, possam servir de indicação de uma norma de Direito Internacional, aplicável a casos de terrorismo internacional, mesmo naquelas hipóteses em que a um Estado podem ser atribuídas atividades criminosas de pessoas físicas sob a sua jurisdição.

27. O julgado que mais tem sido aventado como um precedente de alguma valia, é o Caso do Estreito de Corfu, julgado pela Corte Internacional de Justiça, a 10 de abril de 1949, (entre o Reino Unido e a Albânia) ${ }^{32}$. por sinal, a primeira manifestação daquele tribunal internacional. Tratava-se da determinação dos direitos do Reino Unido de reparação de danos causados por afundamento de navios militares, de passagem pelo Estreito de Corfu, lugar de passagem livre reconhecido pelo Direito Internacional, após o final da II Guerra Mundial, e que se teriam chocado com minas marítimas colocadas pela Albânia, com o propósito de impedir aquela passagem. Ao decidir a favor do Reino Unido, a Corte Internacional de Justiça, baseou-se na aplicação "de certos princípios gerais e bem reconhecidos, tais as considerações elementares de humanidade, mais absolutos ainda em tempo de paz do que em tempo de guerra, o principio da liberdade das comunicações maritimas e a obrigação, para qualquer Estado, de não deixar utilizarse seu território para fins de atos contrários aos direitos de outros Estados" ${ }^{33}$. Contudo, a nosso ver, os fatos do Caso do Estreito de Corfu somente serviriam para casos em que os atos de terrorismo fossem perpetrados a partir do território de um Estado, ou a ele atribuídos, de forma inequívoca (diretamente por atividades de seus órgãos, como no caso da Albânia, cuja atitude, de prevenir, por sinais marítimos de autoridades militares, a aproximação dos navios acidentados, provou sua ligação com o fato de haver minas marítimas nos locais de passagem dos navios). A nosso ver, teria sido mais dificil a atribuição daquele ilicito ao Estado, se o dano tivesse sido ocasionado por comportamentos omissivos das autoridades do Estado, relativamente ao controle de atividades de grupos terroristas sediados em seu território, ou composto por pessoas de sua nacionalidade! $\mathrm{O}$ que dizer-se então, de atos terroristas cometidos por nacionais de um Estado, ou por apátridas, no território de outros Estados ou nos espaços internacionais comuns, ou mesmo

32. Vcja-sc a análise deste Caso, que realizamos no Cap. V de nosso livro já citado, Dircito Intemacional do Mcio Ambiente, Emergência, Obrigações c Responsabilidades, id., ibid.

33. Em nossa tradução livre, do texto transcrito apud: Picrre Michcl Eiscmann, Vincent CoussiratCoustère c Paul Hur Petit Manucl de la Jurisprudence de la Cour Internationale de Justicc, Paris, Éditions

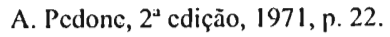


em aviões ou navios sem registro ou sem pavilhão, e nos espaços sem qualquer jurisdição dos Estados (espaço no ou sob o alto mar, ou no espaço sideral)!

28. Enfim, o presente estudo não poderia deixar de examinar um caso recente, que foi apresentado perante a Corte Internacional de Justiça e cuja decisão, criticada por muitos autores, não chegou a atacar o fundo da questão sobre a responsabilidade de um Estado por atos de terrorismo, tendo-se limitado a julgar questão processuais e de medidas cautelares, em particular a questão prévia da competência daquele tribunal em poder examinar atos de outros órgãos da ONU, nomeadamente, as Resoluções ns. 731 (1992) e 748 (1992) do seu Conselho de Segurança. Trata-se do Cașo Lockerbie, ${ }^{34}$ como ficou conhecido, e que opôs, no polo ativo, a Líbia e no pólo passivo, os EUA e o Reino Unido, cuja decisão final sobre matéria processual, (a qual se resumiu a julgar sobre a competência da Corte Internacional de Justiça) foi por esta prolatada a 14 de abril de $1992,{ }^{35}$ não tendo havido qualquer seguimento do caso, desde então.

29. A observância da cronologia dos fatos, no presente caso, é fundamental para a análise da sentença da Corte Internacional de Justiça, conforme se verá. A 21 de dezembro de 1988, uma explosão de um avião comercial, em pleno vôo, da empresa norte-americana PanAm (vôo 103) ocorre sobre a cidade de Lockerbie, na Escócia, num atentado em que morreram 279 passageiros; recorde-se que, naqueles tempos, o mundo já se achava estupefato com outro atentado contra a aviação civil, em Níger, ao vôo 772, da empresa UTA, a 17 de setembro daquele ano, com a morte de 171 pessoas. A 14 de novembro de 1991, um tribunal federal de primeiro grau dos EUA (para o Distrito de Colúmbia), juntamente com o Procurador Geral da Escócia, anunciaram a expedição da mandatos de prisão contra dois cidadãos líbios, considerados como autores do atentado em Lockerbie, e o enviaram por via diplomática à Líbia; em declarações públicas posteriores, tanto o Governo do Reino Unido, quanto o dos EUA, e mais o Governo de França, insistiam para que a Líbia cooperasse na investigação da autoria daqueles atentados e facilitasse $\mathrm{o}$ acesso a todos os documentos e provas para a descoberta da verdade (nada havendo, contudo, no que se referisse a pedidos formais de extradição).

30. A resposta da Líbia consistiu na indicação de dois magistrados líbios que iniciaram uma investigação, conforme a legislação daquele país, os quais, em

34. O nome oficial do caso ć: "Caso Relativo a Questöes de Interpretação e de Aplicação da Convenção de Montreal de 1971, Resultante do Incidente Aéreo de Lockerbie (Grande Jamahiriya Árabe Popular Socialista da Libia versus Reino Unido e Grande Jamahiriya Árabe Popular Socialista da Libia versus EUA).

35. Textos das decisões $\mathrm{c}$ amplos comentários sobre os fatos são encontráveis na Revuc Génćralc de Droit Intcrnational Public, Pcdonnc, Paris, 1993, pp. 689-726. Vcja-sc a versão cm inglês In: Internet, no "sitc": www.icj-cij.org. 
contato com autoridades do Reino Unido, EUA e França, ofereceram sua cooperação. Estes três países, recorde-se, membros permanentes do Conselho de Segurança da ONU, com poder de veto, não-só insistiram nos seus pedidos públicos, como levaram o assunto perante o referido Conselho de Segurança. Na verdade, este Conselho, a 21 de janeiro de 1992, adotaria, por unanimidade, por proposta conjunta dos referidos três países, a Resolução n. 731 (1992), pela qual se lamenta que o Governo líbio não tenha respondido ainda às petições encaminhadas, no sentido de que coopere na determinação da responsabilidade pelos atos terroristas praticados contra as aeronaves civis, nos vôos 103 da PanAm e 771 da UTA "e exorta-se o Governo libio a que proporcione, de imediato, uma resposta completa e efetiva a tais petições, a fim de contribuir para a eliminação do terrorismo internacional". Note-se que, igualmente, não há qualquer referência formal a um dever de a Líbia extraditar os possíveis culpados.

31. Nos primeiros meses de 1992, seguem-se várias propostas da Líbia, seja de uma investigação por pessoas neutras, em território líbio, seja a da intervenção de um tribunal internacional "ad hoc" seja mesmo a entrega dos suspeitos ao Secretário Geral das Nações Unidas ou ao Secretário Geral da Liga dos Estados Árabes. Tais propostas se chocam com a determinação firme do Reino Unido e dos EUA de que os suspeitos fossem entregues aos seus respectivos Governos, para julgamento em um dos países.

32. A 03 de março de 1992, a Líbia apresenta à Corte Internacional de Justiça uma reclamação contra o Reino Unido e os EUA, relativa à interpretação e aplicação da Convenção de Montreal de 23/10/1971, "para a Repressão de Atos llicitos contra a Segurança da Aviação Civil", ao mesmo tempo de que solicita a adoção, por aquele tribunal, de medidas provisórias, ao amparo do art. 41 do seu Estatuto. ${ }^{36}$ Relembre-se que a Convenção de Montreal reconhece a regra de Grotius do "aut dedere, aut punire" (embora deixe aos Estados a caracterização de um fato como crime político, o que impediria a extradição de suspeitos ou condenados, conquanto ainda persista a obrigação de julgamento, segundo seu ordenamento jurídico interno). ${ }^{37}$ Deve destacar-

36. Assim sc lê o art. 41 do Estatuto da Cortc Internacional de Justiça: " \$ lo. A Corte terá a faculdade de indicar, se assim julgar que as circunstâncias o exigem, quaisquer medidas provisórias que devam ser tomadas para preservar os direitos de cada parte. $\$ 20$. Antes que a sentença seja proferida, as partes $e$ o Conselho de Segurança deverão ser informados imediatamente das medidas sugeridas". Texto apud Vicentc Marotta Rangel, Dircito c Relaçõcs Internacionais, id., ibid., p. 80.

37. Trata-se do art. 7o da Convenção de Montrcal, assim redigido, em nossa tradução livre: " $O$ Estado contratante em cujo território seja descoberto o autor presumido de uma das infrações, no caso de não proceder à extradição desta pessoa, deverá submeter a julgamento, sem qualquer exceção e nas hipóteses de haver ou não haver a infração sido cometida em seu território, às autoridades competentes para o exercicio da ação penal. Tais autoridades deverão decidir, nas mesma condições que qualquer infiação de direito comum de caráter grave, conforme as leis deste Estado" Texto transcrito na sentença da CIJ, cf. Internet, no "site" citado. 
se, igualmente, o fato de que a Líbia acionou a jurisdição da Corte Internacional de Justiça, tendo por fundamento a existência de uma cláusula de soluções de litígios entre as partes contratantes daquela Convenção de Montreal, a cláusula 14, assim redigida: "Qualquer controvérsia entre os Estados contratantes, concernentes à interpretação ou à aplı xção da presente Convenção, que não tenha sido resolvida por negociações, será resolvida por arbitragem, a pedido de uma delas. Se nos seis meses que se sigam à data do pedido de arbitragem as Partes não cheguem a um acordo sobre a organização da arbitragem, qualquer delas pode submeter a controvérsia à Corte Internacional de justiça, através do depósito de um pedido, conforme o Estatuto da Corte".

33. A 31 de março de 1992, apenas há três dias do encerramento das primeiras audiências da Corte, o Conselho de Segurança das Nações Unidas adotaria a Resolução n. 748 (1992), apresentada pelos EUA, França e Reino Unido, aprovada com cinco abstenções de membros não permanentes daquele Conselho, segundo a qual: a) são reiterados os termos da anteriormente mencionada Resolução n. 731 (1992); b) o Conselho de Segurança "decide também que o Governo da Libia deve comprometer-se definitivamente a colocar um fim a todas as formas de ação terrorista e a toda assistência a grupos terroristas e a demonstrar, prontamente, mediante atos concretos, sua renúncia ao terrorismo", ${ }^{38}$ e, enfim, c) decide aquele Conselho de Segurança estabelecer um prazo fatal até 15 de abril de 1992 para que a Libia proceda à entrega de seus nacionais, sob pena da imposição de sanções, a serem aplicadas por todos os Estados das Nações Unidas, consistentes no isolamento aéreo daquele país e na proibição da venda de armas e equipamentos militares, a partir daquela data.

34. No seu curso, o Caso prosseguia na Corte Internacional de Justiça, tendo esta proferido um Despacho interlocutório a 14 de abril de 1992, em que rejeitava, após as citadas primeiras audiências das partes, o pedido de medidas preliminares conservatórias, feito na base do referido art. 41 do Estatuto, com os argumentos de que as circunstâncias, na espécie, não eram de molde a exigir o exercício do poder de a Corte decretar as referidas medidas.

35. Enfim, apresentadas as respostas e as razões dos reclamados, EUA e Reino Unido, e as contra-razões da reclamante, a Líbia, bem como após haverem-se realizado audiências públicas a 13 e 22 de outubro de 1997, a Corte Internacional de

38. Texto cf. M. Paz Andrćs Saćnz de Santa Maria, ““ "De Maximis non Curat Praetor”? El Consejo de Seguridad y el TIJ en el Asunto Lockerbie. In: Revista Española de Derccho Internacional, CSIC, Madri 1992, v. : XLIV-1002, num. 2 (julio-dicicmbre), p. 334. 
Justiça, a 14 de abril de 1992, prolataria sua sentença, que foi adotada, em todas as decisões parciais, por maioria de votos dos 16 juízes que compuseram aquele tribunal, para o julgamento "sub studio" (sendo votos dissidentes constantes em todas as decisões parciais, os do juiz Schwebel, Presidente da CIJ, do juiz Oda e de Sir Robert Jennings, juiz "ad hoc" pelo Reino Unido). Em virtude de haver o Presidente do Tribunal sido voto vencido, presidiu a sessão, o Vice-Presidente da CIJ, o juiz Weeramantry.

36. As alegações preliminares de incompetência da Corte Internacional de Justiça que os Estados reclamados tinham apresentado, de que a reclamante, Líbia, não teria cumprido com as exigências da cláusula 14 da Convenção de Montreal (esgotamento das negociações e exaustão de procedimentos de arbitragem, antes do acionamento da jurisdição daquele tribunal internacional), foram rejeitadas. $\mathrm{ACIJ}$ julgou que, "verbis", "a controvérsia que existiria entre as Partes não poderia ter sido resolvida nem pela via de negociações, nem ser submetida à arbitragem, na aplicação da Convenção de Montreal, e que a recusa dos demandados de tomar parte numa arbitragem para resolver tal controvérsia, exoneraria a Libia de qualquer outra obrigação, nos termos do $\$ 1^{\circ}$ da cláusula 14 da Convenção, de observar o prazo de seis meses, a contar do pedido de arbitragem, antes de solicitar providências à Corte ${ }^{39}$ "

37. Importante acentuar o teor das razões das reclamadas, no que se refere ao seu pedido de uma decisão judicial, de que não assistiria direito à Líbia, de um julgamento pela CIJ, na base da aplicação da Convenção de Montreal. Conforme o resumo daquelas razões, feito pela CIJ, verbis: "Nos procedimentos, o Reino Unido, no entanto, alegou que, mesmo que a Convenção de Montreal houvesse conferido à Libia direitos que ela reivindica, estes não poderiam ser exercidos, na espécie, pelo motivo de que teriam sido suplantados pelas Resoluções ns. 748 (1992) e 883 (1993) do Conselho de Segurança que, em virtude do art. 25 e do art. 103 da Carta das Nações Unidas, prevalecem sobre quaisquer outros direitos criados pela Convenção de Montreal. A reclamada, assim, aduziu a que, pelo fato da adoção de tais Resoluções, a única controvérsia que doravante existiria, oporia a Libia ao Conselho de Segurança; ora, tratar-se-ia, à evidência, de uma controvérsia que não entraria nas previsões do $\$ 1^{\circ}$ do art. 14 da Convenção de Montreal e a qual a Corte não poderia, desde logo, conhecer"40

38. Na verdade, para aquilatar-se a força de tais argumentos do Reino Unido e dos EUA, e que poderiam ter sido relevantes para a decisão da Corte, quanto

39. Texto, cm nossa tradução livre, conforme Internct: www,icj.cij.org/cijwww/cdccisions/ csummarics/cluksommairc199802227.html, in p. 2, in fine.

40. Texto, cf. Internet, id. Ibid., p. 4 de 10. 
ao conhecimento ou não do mérito da questão (conforme se verá, a seguir, aquelas Resoluções do Conselho de Segurança não poderiam ter operado seus efeitos, pois a Corte os considerou ineptos, uma vez que as citadas Resoluções foram votadas, em data posterior ao ajuizamento da questão, perante a mesma), é necessário ter presentes os termos dos referidos art. 25 e art. 103 da Carta da ONU. Ambos os artigos enfatizam a importância das deliberações do Conselho de Segurança da ONU, como se sabe, o órgão central das Nações Unidas, no que se refere à manutenção da paz e da segurança internacionais, nos seguintes termos: "Os membros das Nações Unidas concordam em aceitar e executar as decisões do Conselho de Segurança, de acordo com a presente Carta”(art. 25) e "No caso de conflito entre as obrigações dos membros das Nações Unidas em virtude da presente Carta e as obrigações resultantes de qualquer outro acordo internacional, prevalecerão as obrigações assumidas em virtude da presente Carta" (art. 103).

39. Neste particular, a Corte julgou que a exceção de incompetência apresentada pelas reclamadas, com base nas mencionadas Resoluções ns.748(1992) e 883 (1993), por terem sido estas aṕrovadas após o depósito do pedido da Líbia, endereçado à Corte, em 03 de março de 1992, não poderiam modificar uma competência já constituída, e, nos termos da sentença, "verbis", "conforme a uma jurisprudência constante, se a Corte era competentes naquela data, ela continua a ser competente; a intervenção posterior das mencionadas resoluções, não poderiam afetar uma competência já estabelecida ${ }^{4 l}$ " Portanto, o pedido da Líbia poderia ser examinado no mérito, em virtude do reconhecimento da competência da CIJ, contra as alegações preliminares das reclamadas.

40. Tais argumentos serviriam, igualmente, para rejeitar as alegações apresentadas pelas reclamadas, como excipientes, de que uma decisão preliminar de não conhecimento das reclamações da Líbia, com base na citada preeminência dos mencionados artigos da Carta da ONU, constituiria "matéria exclusivamente preliminar" nos termos do art. 79 do Regimento da Corte, teria assim privado o pedido da Líbia de qualquer objeto, o que facultaria aquela Corte julgar o pedido "in limine", sem conhecimento do fundo do litígio. A CIJ decidiria, por maioria de votos, que, "verbis": "se ela devesse estatuir sobre esta exceção, ela estaria estatuindo, irremediavelmente, sobre o fundo, ou, ao invocar os beneficios do art. 79 do Regimento, o(s) demandado(s) colocariam em funcionamento um procedimento que visaria, precisamente, a impedir a Corte de fazê-lo...conclui portanto, que aquela exceção não tem um "caráter exclusivamente preliminar" nos termos daquele artigo, [e que] tendo estabelecido

41. Em nossa tradução livre, conforme texto da sentença no "site" da lnternet, citado no rodapć anterior, p. 4 de 10 . 
sua competência, conclui pelo conhecimento do pedido, podendo a Corte pronunciarse sobre tal exceção, no quadro de seu exame do fundo da questão" ${ }^{42}$

41. Finalmente, a Corte Internacional de Justiça, tendo-se declarado competente para conhecer a matéria de fundo da controvérsia, determinou que fixará, ulteriormente, os prazos para o prosseguimento do julgamento.

42. Infelizmente, não seria esta a oportunidade de analisarmos os interessantes votos dissidentes naquela sentença, de 14 de abril de 1992, da Corte Internacional de Justiça, sobre preliminares de competência, no Caso Lockerbie (votos que indicam importantes posicionamentos dos juizes daquele Corte, no relativo a seus poderes, face aos poderes do Conselho de Segurança).

43. De qualquer maneira, uma análise da doutrina que analisou aquela sentença, revela uma certa decepção de seus autores, pois a grande discussão sobre a contribuição que a Corte Internacional de Justiça poderia ter dado à luta contra o terrorismo internacional, resumiu-se a discutir aspectos processuais, com poucos reflexos sobre a matéria de fundo discutida.

44. É nosso sentimento de que, mesmo numa futura sentença sobre a substância da matéria, aqueles percalços que apontamos, no correr deste trabalho, deverão aparecer, possivelmente pelo fato de que, a nosso ver, a luta contra "o terrorismo de Estado" ou contra o "terrorismo contra Estado" deva seguir o mesmo caminho que percorreram os Direito Humanos.

45. Se o percurso percorrido pelos Direito Humanos desembocou no reconhecimento de direitos subjetivos de individuos, frente a tribunais internacionais de proteção dos mesmos, acreditamos que, em matéria de reconhecimento da responsabilidade individual criminal, frente a tribunais internacionais, em particular no caso da Corte Internacional de Justiça, deva se esperar por profundas modificações legislativas nos textos internacionais relevantes ou, o que é menos provável, pela intervenção de uma jurisprudência verdadeiramente revolucionária, frente às normas $\mathrm{e}$ princípios vigentes sobre sua competência e jurisdição. Acreditamos que, sem modificações de grande porte nos textos fundamentais que legitimam a competência e jurisdição da Corte Internacional de Justiça, dificilmente poderá ela julgar ações criminosas, em aspectos que envolvem o denominado "terrorismo de Estado" e, mais ainda, o denominado "terrorismo contra o Estado", este, um fenômeno sem fisionomia e com pouca probabilidade de ser atribuível a um Estado, ainda a única pessoa que tem acesso, no pólo passivo, à jurisdição daquele tribunal internacional.

São Paulo, julho de 2003.

42. Texto conforme INTERNET, id., ibid., p. 6 de 10. 
Bibliografia

Eisemann, Pierre Michel, Vincent Coussirat-Coustère e Paul Hur Petit Manuel de la Jurisprudence de la Cour Internationale de Justice, Paris, Éditions A. Pedone, $2^{a}$ edição, 1971.

Guillaume, Gilbert Terrorisme et le Droit International. IN: Recueil des Cours, Academia de Direito Internacional, Haia, 1989, v. II (tomo 215), pp. 291-416.

Lindgren Alves, J. A. Os Direitos Humanos como Tema Global, São Paulo, Perspectiva, e Brasília, Fundação Alexandre de Gusmão, 1994.

Mello, Celso D. de Albuquerque Direito Penal e Direito Internacional, Rio de Janeiro, Freitas Bastos, 1978.

Nations Unies Résumé des Arrêts, Avis Consultatifs et Ordonnances de la Cour Internationale de Justice, 1948-1991, Nova York, Nations Unies, 1992.

Rangel, Vicente Marotta Direito e Relações Internacionais, São Paulo, Editora Revista dos Tribunais, $6^{\text {a }}$ edição revista e atualizada.

Soares, Guido F. S. "Solução e Prevenção de Litigios Internacionais: Tipologias e Caracteristicas Atuais" In: Araminta de Azevedo Mercadante e José Carlos de Magalhães, coordenadores, Solução e Prevenção de Litígios Internacionais, v. II, São Paulo, NECIM-Projeto CAPES e Porto Alegre, Livraria do Advogado Editora, 1999.

Soares, Guido F. S. “União Européia, Mercosul e Proteção dos Direitos Humanos" In Procuradoria Geral do Estado de São Paulo e Faculdade de Direito da PUC-SP, Direitos Humanos e Mercosul, São Paulo, no prelo.

Soares, Guido Fernando Silva, Direito Internacional do Meio Ambiente: Emergência, Obrigações e Responsabilidades. São Paulo, Atlas, 2001.

Sorto, Fredys Orlando “América Central: Relações Internas e Crise Política: Soluções Pacíficas”, Dissertação de Mestrado em Direito Internacional, defendida a 07/VI/1991, na Faculdade de Direito da USP (Orientador: Prof. Dr. José Roberto Franco da Fonseca).

Artigos em Revistas Especializadas

Andrés Saénz de Santa Maria, M. Paz “De Maximis non Curat Praetor"? El Consejo de Seguridad y el TIJ en el Asunto Lockerbie. In: Revista Española de Derecho Internacional, CSIC, Madri, 1992, v. : XLIV-1002, num. 2 (julio-diciembre), p. 327-50.

Bretton, Philippe Remarques sur le "Jus in Bello" dans la Guerre du Golfe (1991). In: Annuaire Français de Droit International, Paris, Editions du CNRS, v. XXXVII, 1991, pp. 139-164.

Cottereau, Gilles De la Responsabilité de l'Iraq selon la Résolution $687 d u$ Conseil de Sécurité. IN: Annuaire Français de Droit International, Paris, Editions du CNRS, v. XXXVII, 1991, pp. 100-117.

Eckert, M.D., William G. The Lockerbie Disaster and Other Aircraft Breakups in Midair. In: The American Journal of Forensic Medicine and Pathology, Nova York, Raven Press, v. 11, n. 2, junho 1990, pp. 93-101. 
Fraysse-Druesne, Ghislaine, La Convention Européenne pour la Répression du Terrorisme. IN: Revue Générale de Droit International Public, Paris, A, Pedone, 1978, pp. 970-1.023.

Koskenniemi, Martti Le Comité des Sanctions (Créé par la Résolution 661(1990) dı Conseil de Sécurité. In: Annuaire Français de Droit International, Paris, Editions du CNRS, v. XXXVII, 1991, p.119-137.

Silva, Fernando Fernandes da, "A Proteção do Refugiado no Ordenamento Juridico Nacional: Fundamentos Constitucionais e as Medidas Legislativas e Administrativas Aplicáveis" In: Revista Trimestral de Direito Público, São Paulo, Malheiros (no prelo).

Soares, Guido F. S. As ONGs e o Direito Internacional do Meio Ambiente" In: Revista de Direito Ambiental, São Paulo, Ed. Revista dos Tribunais, ano 5, n. 17, janeiro-março, 2000, pp. 21-64.

Soares, Guido F. S. "O Meio Ambiente e a Justiça no Mundo Globalizado". In: Justiça Penal: Críticas e Sugestões; 10 Anos da Constituição e a Justiça Penal: Meio Ambiente, Drogas, Globalização e o Caso Pataxó. Coordenador: Jacques de Camargo Penteado. São Paulo, Editora Revista dos Tribunais, 1998, pp. 65-118.

Sorel, Jean-Marc Les As de la C.I.J du 27 Février 1998 sur les Exceptions Préliminaires das les Affaires Dites de Lockerbie: et le Suspense Demeure...In: Revue Générale de Droit International Public, Paris, A, Pedone, 1998, pp. 685-721.

Vallée, Charles La Convention Européenne pour la Répression du Terrorisme. In: Annuaire Français de Droit International, Paris, Editions du CNRS, v. XXII, 1976, pp. 756-786.

Weckel, Philippe Le Chapitre VII de la Charte et Son Application par le Conseil de Sécurité. IN: Annuaire Français de Droit International, Paris, Editions du CNRS, v. XXXVII, 1991, pp. 165-202. 